\title{
4
}

\section{SERVIÇO SOCIAL E CRISE ESTRUTURAL DO CAPITAL EM TEMPOS DE PANDEMIA}

\author{
Social Work and capital structure crisis in a pandemic moment
}

\author{
Angélica Luiza Silva Bezerra* \\ https://orcid.org/0000-0003-3649-6143 \\ Milena Gomes de Medeiros** \\ https://orcid.org/0000-0002-8630-6195
}

\begin{abstract}
RESUMO
O presente artigo trata de alguns elementos constitutivos do processo de crise estrutural do capital e suas implicações para o Serviço Social, sob a perspectiva das políticas sociais e do trabalho no contexto da pandemia mundial da COVID-19. Do ponto de vista dos procedimentos metodológicos, utilizou-se uma pesquisa bibliográfica com o auxílio de dados sobre a temática, a partir das indicações do Boletim de Conjuntura do Departamento Intersindical de Estatística e Estudos (DIEESE) de maio de 2020, Relatório Especial COVID-19 da Comissão Econômica para a América Latina e o Caribe (CEPAL/OIT) de 2020, nota do CFESS intitulada orientações sobre o exercício profissional diante da pandemia do coronavírus (COVID-19) de 2020, entre outros. Sob o prisma de resoluções e portarias e de novos procedimentos de atuação na pandemia do COVID-19, destacam-se dois eixos que incidem sob o Serviço Social: o trabalho que se precariza no âmbito dos serviços e as demandas e competências que passam a exigir do profissional um novo direcionamento ante os impasses da burocratização da vida social e da legitimação de competências que (des)caracterizam o objeto de trabalho no campo da questão social e das politicas sociais, à luz das diretrizes e princípios do Código de Ética de 1993.
\end{abstract}

\section{PALAVRAS-CHAVE}

Crise Estrutural. Pandemia da COVID-19. Burocratização. Serviço Social.

\section{ABSTRACT}

This article is about some of the most important elements of structure crisis process and its consequences for the Social Work, from the perspective of social and labor policies in this pandemic moment because of the COVID-19. From the point of view of methodologicak procedures, a bibliographic research was used with the aid of data on the theme, from the indications of the 2020 Iterunion Department of Statistics and Studies (DIEESE) Conjuncture Bulletin, COVID-19 Special Report of The Economic Commission For Latin America and the Caribbean (ECLAC/ILO), a CFESS note entitled guidelines on profissional practice in the

\footnotetext{
* Assistente Social. Doutora em Serviço Social. Docente do curso de Serviço Social Campus Arapiracal Unidade Palmeira dos Índios da Universidade Federal de Alagoas. (UFAL, Palmeira dos Índios, Brasil). Rua Sonho Verde, $s / \mathrm{n}^{\circ}$, Eucalipto, Palmeira dos índios (AL), CEP.: 57309-005. E-mail: angelica.bezerra@palmeira.ufal.br.

** Assistente Social. Doutora em Serviço Social. Docente do curso de Serviço Social da Universidade Federal de Alagoas. (UFAL, Maceió, Brasil). Av. Lourival Melo Mota, s/nº, Tabuleiro do Martins, Maceió (AL), CEP.: 57072-900. E-mail: milenagmedeiros@yahoo.com.br.
}

DOI 10.22422/temporalis.2021V21n41p53-69 Commons Atribuição 4.0 Internacional (https://creativecommons.org/licenses/by/4.o/deed.pt_BR), que permite copiar e redistribuir o material em qualquer suporte ou formato, bem como adaptar, transformar e criar a partir deste material para qualquer fim, mesmo que comercial. O licenciante não pode revogar estes direitos desde que você respeite os termos da licença. 
face os the coronavirus pandemic (COVID-19) of 2020 among others. Under the prism of resolutions and a new action because of the COVID-19, two facts stand out of the Social Service: work that is precarious in services and demands, and the demand of a new direction from the professionals against the impasses of bureaucratization of social life and the legitimation of the competencies that caracterize the worked object in the social issues field and social policies, guided by the principles of the Code Ethics from 1993.

\section{KEYWORDS}

Structure Crisis. COVID-19 Pandemic. Bureaucratization. Social Work.

\section{INTRODUÇÃO}

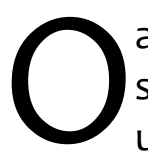

artigo Serviço social e crise estrutural do capital em tempos de pandemia aborda sobre a crise estrutural do capital e suas implicações para o Serviço Social, sob uma perspectiva das políticas sociais e do trabalho no contexto da pandemia mundial da COVID-19. Do ponto de vista dos procedimentos metodológicos, utilizou-se uma pesquisa bibliográfica com o auxílio de alguns dados sobre a temática, a partir das indicações do Boletim de Conjuntura do Departamento intersindical de estatística e estudos (2020) de maio de 2020, Relatório Especial COVID-19 da Comissão Econômica para a América Latina e o Caribe (COMISIÓN ECONÓMICA PARA AMÉRICA LATINA Y EL CARIBE, 2020) de 2020, da nota do Conselho Federal de Serviço Social (2020, p. 1) intitulada ORIENTAÇÕES SOBRE O EXERCÍCIO PROFISSIONAL DIANTE DA PANDEMIA DO CORONAVÍRUS (COVID-19) de 2020, entre outros, para problematizar as contradições e expressões da relação capital $x$ trabalho na atualidade pandêmica em que só no Brasil, a COVID-19, já ceifou a vida de 484,504 milhões de pessoas; num total de 105,292 milhões de casos.

Em tempos de pandemia mundial causada pelo novo coronavírus, muitos desafios são postos ao conjunto da sociedade, em especial aos/às trabalhadores/as e às políticas públicas. A humanidade tem experimentado um momento diferenciado da história, no qual a crise estrutural do capital tem ativado, desde os anos de 1970, seus limites, impulsionando outras crises setoriais, como a da saúde pública, a evidenciar um colapso econômico, político, social e cultural em todo o globo terrestre.

O novo coronavírus, por se tratar de um fator de transmissão altamente contagioso e por seu alastramento no mundo, foi logo identificado como uma pandemia, conforme as determinações da Organização Mundial da Saúde (COMISIÓN ECONÓMICA PARA AMÉRICA LATINA Y EL CARIBE, 2020). Dada a sua gravidade, sugeriu-se aos países que seus governantes tomassem medidas de isolamento social e paralisação de alguns postos de trabalho não essenciais, com a redução da jornada de trabalho em alguns setores, porém mantendo a circulação das mercadorias através do mercado virtual.

Com a diminuição da produção das empresas e o trabalho sob o regime de rodízio, o desemprego acelerou significativamente. De acordo com o Boletim de Conjuntura do Departamento Intersindical de Estatística e Estudos Socioeconômicos (DIEESE) de maio de 2020, estima-se que cerca de 17 milhões de trabalhadores estarão desempregados no Brasil até o final deste ano. Segundo dados do Instituto Brasileiro de Geografia e Estatística (2021), a taxa de desemprego, no primeiro trimestre de 2021 atingiu 14,8\%. Com o aumento do desemprego, a tendência é a disseminação cada vez maior do trabalho 
informal sem direitos trabalhistas e a legitimação de novas modalidades de trabalho, na forma do trabalho híbrido e/ou remoto, como uma alternativa para reduzir a circulação de pessoas.

Apesar da ampla gama de problemas que a humanidade enfrenta no contexto da pandemia, não se pode deixar de anotar que tais expressões da questão social são de ordem estrutural e, portanto, fazem parte de uma cadeia mistificadora de contradições que mantém intocável a estrutura desumanizante do sistema do capital. Torna-se alarmante a ideia de que a chamada "crise da pandemia" está sendo considerada como causa da crise do emprego e da miséria, maquiando as evidências dos defeitos destrutivos da ordem do capital.

Destarte, Mészáros (2012), nos esclarece que: "O sistema do capital se articula numa rede de contradições que só se consegue administrar mediante, ainda assim durante curto intervalo, mas que não se consegue superar definitivamente" (MÉSZÁROS, 2012, p. 19, grifos do autor). Conforme o autor, a raiz dessa contradição acha-se expressa no antagonismo entre capital e trabalho. Na pandemia, esse antagonismo é redimensionado, repondo as tendências desumanizantes do capitalismo na vida não somente do trabalhador, mas da humanidade como um todo. As necessidades verdadeiramente humanas são sempre submetidas aos interesses do lucro e do desenvolvimento econômico.

Ainda nas palavras do autor:

\begin{abstract}
Hoje não há sentido em se falar de um "desenvolvimento geral da produção" associado à expansão das necessidades humanas. Assim, dada a forma em que se realizou a deformada tendência globalizante do capital - e que continua a se impor -, seria suicídio encarar a realidade destrutiva do capital como o pressuposto do novo e absolutamente necessário modo de reproduzir as condições sustentáveis da existência humana (MÉSZÁROS, 2012, p. 21, grifos do autor).
\end{abstract}

Enquanto isso, as expressões da questão social só se agravaram sob o controle da administração do Estado. Em nome do desenvolvimento econômico e social, a estratégia de isolamento e redução dos postos de trabalho da (OMS) impactou significativamente na economia mundial, que já vinha sofrendo problemas estruturais. Todavia, o mercado mundial retomou paulatinamente as atividades de produção, do comércio e dos serviços com protocolos de proteção e utilização de equipamentos de segurança. O inevitável retorno trouxe para o debate novas discussões e incertezas quanto à estabilidade nos empregos e a um retorno seguro.

A pandemia impactou decisivamente nos setores de serviços das áreas da saúde e da assistência social, e posteriormente na educação, com o processo de planejamento para o retorno das atividades. A definição pela Lei n 13.979, de 6 de fevereiro de 2020, dos serviços públicos e atividades essenciais respaldou a atuação da(o) assistente social na linha de frente da pandemia. Como profissional da saúde, foi preciso redefinir suas ações em face do atendimento à população usuária dos serviços públicos e privados. Ademais, além de atuar de forma presencial em setores como a saúde, também redefiniu suas ações na prestação de serviços de forma parcialmente remota. 
A atuação profissional por meio do trabalho remoto colocou para a cena contemporânea novos desafios e o aprimoramento para a intervenção profissional, além do conhecimento das competências teórico-metodológicas, ético-políticas, técnico-operativas e investigativas. Precisou-se de conhecimentos técnicos de proteção e do manuseio de tecnologias de informações, bem como na construção de instrumentos e técnicas de atuação que se enquadrassem na nova modalidade de intervenção, de forma excepcional.

O momento histórico atual dos reflexos da crise estrutural na pandemia pontua e repõe movimentos e tensões no arcabouço ideológico, teórico e prático-cultural - quer seja no campo dos projetos societários, quer seja no das especializações do trabalho no âmbito da divisão sociotécnica. Estas devem ser refletidas e requalificadas, não só no debate das ideias, mas, sobretudo, no que diz respeito às ações práticas cotidianas dos sujeitos coletivos e profissionais.

Este contexto recoloca questões que no arsenal da particularidade teórico-metodológica e prático-interventiva da profissão já foram debatidas (NETTO, 2006; MOTA, 2008) e supostamente superadas, o que de modo algum significa que foram eliminadas do terreno sócio-histórico da profissão, já que se observa na quadra sócio-histórica dos anos 2020 uma reatualização de traços geneticamente postos pela cultura conservadora, reposta através da precarização do trabalho e dos serviços como uma das alternativas para minorar os efeitos da atual fase do capitalismo na pandemia.

Tais elementos vêm sendo reordenados pela dominância cultural da decadência ideológica da pós-modernidade, implicando abordagens reducionistas e equivocadas no arcabouço das produções teóricas, que no âmbito da própria tradição marxista recaem no ecletismo e no epistemologismo. No que concerne ao exercício, repõe-se a ideia de que o conhecimento verdadeiro é aquele que se traduz num resultado prático imediato, útil e instrumental. Este tipo de conhecimento ainda faz parte da categoria profissional, ganhando status de verdade ao ser reiteradamente afirmado pela lógica cultural da pós-modernidade no âmbito da pandemia.

Desse modo, vêm ganhando espaço as reflexões trazidas pela chamada pósmodernidade, que adotam o sentido do fragmento como central para analisar a produção e a reprodução social. Esta dominância foi qualificada por Lukács (1979, p. 98 "como a decadência ideológica do pensamento burguês, dada a apreensão do real na sua fenomenalidade, na aparência". Tal tipo de conhecimento vem determinando a reflexão do real e suas respostas. Parte de uma análise que não prima pela articulação entre as dimensões da universalidade, singularidade e particularidade como mediações necessárias para compreender a natureza ontológica e a funcionalidade do objeto em estudo.

Braz (2012) afirma que o atual tempo histórico abriu as portas para uma onda conservadora resultante da cultura ideológica da pós-modernidade, em que predominam duas formas de conservadorismo: um conservadorismo de direita, que afirma o fim da história, e outro conservadorismo de esquerda, que aprofunda o possível mediado pelo entendimento das várias verdades, dos vários métodos, da centralidade do sujeito nas 
abordagens, a partir de suas representações e que não considera a dinâmica/processualidade do objeto na realidade.

No atual momento histórico caracterizado como capitalismo pandêmico (SUDRÉ, 2020)', o conservadorismo é perpetuado para a manutenção da ordem burguesa, com o ajustamento de práticas que assegurem a dinâmica do sistema do capital. Como forma de garantir a proteção à vida e reduzir a aglomeração e circulação de pessoas, é exigida dos profissionais uma intervenção seletiva e previamente agendada. Desta maneira, presencia-se um momento histórico no qual, em nome da sobrevivência humana, a precarização e a burocratização da vida social são tidas como saídas estratégicas para a crise estrutural no contexto da pandemia.

\section{A CRISE ESTRUTURAL DO CAPITAL E A PANDEMIA}

Longe de esgotar todas as determinações constantes da processualidade dialética e histórica das crises do capitalismo, a crise que assola desde os anos de 1970 todos os países do capitalismo central e periférico vem, cada vez mais, caracterizando um capitalismo que "[...] está se confrontando com seus limites históricos [...]" (ARCARY, 2011, p. 1, grifos nossos) ao "[...] transformar suas potencialidades positivas em realidade destrutiva [...]” (MÉSZÁROS, 2002, p. 614, grifos nossos).

Deste modo, chegou-se a um ponto na história em que se torna indispensável à reflexão sobre a irracionalidade da sociedade capitalista. O sistema do capital ao longo da história sempre se reinventou, buscando estrategicamente o aumento dos seus lucros em detrimento da sobrevivência humana. Desde a acumulação primitiva, o sistema do capital expressou sua contradição na forma da desumanidade do trabalho assalariado. A força de trabalho, apesar de sua importância para a produção, era ativa até a exaustão prematura numa jornada de trabalho excessiva e esgotante. "O capital não tem a menor consideração pela saúde e duração de vida do trabalhador, a não ser quando é coagido pela sociedade a ter consideração" (MARX, 1983, p. 215).

O atual momento histórico é expresso pela pandemia da COVID-19, considerado inédito na história dos homens por seus impactos serem manifestos nos sistemas de saúde, mas pela repercussão na vida de setores mais vulnerabilizados da sociedade, escancarando os problemas estruturais do sistema do capital com a disseminação da instabilidade econômica no mundo. Apesar de não ser a primeira pandemia da história, tem se apresentado como a mais brutal por sua dimensão catastrófica sem precedentes. Além de estratégias para a contenção do vírus, a economia mundial em recessão torna-se uma barreira para o objetivo central do capital, exigindo novos ajustes.

Nesta direção é recolocado um processo regressivo, com consequências sociais, culturais e políticas no âmbito das condições de vida e de trabalho, ou no que Mészáros (2002) chama de barbarização da vida social - momento em que o capital vive uma fase de ascendência histórica esgotada, com soluções cada vez mais assistenciais e militarizadas por parte do Estado capitalista.

\footnotetext{
${ }^{1}$ Termo utilizado por Ricardo Antunes.
} 
Os defeitos estruturais do sistema do capital são repostos na pandemia, pois a crise estrutural penetrou no metabolismo social do sistema, ou seja, este tipo de crise conseguiu atingir os fundamentos do desenvolvimento capitalista por alcançar em escala global o desenvolvimento das forças produtivas do trabalho, além de atingir a totalidade da força de trabalho - independentemente de sua qualificação profissional - no tocante ao aumento do desemprego e da precarização do trabalho, na forma de terceirização e trabalho temporário (MÉSZÁROS, 2002).

A crise não se restringe à sua dimensão econômica, mas abarca a dimensão da reprodução social e seus processos sociopolíticos institucionais, como também a singularidade da vida cotidiana dos homens/mulheres. Esta crise atinge tanto a esfera econômica como a social e a cultural.

Apreender hoje a crise sistêmica/estrutural do capital requer entender que ela ativa dois elementos antagônicos e associados, a saber: a restauração capitalista e a barbárie, instaurando "novos/velhos tempos conservadores". Isso, para Alves (2011), significa o sociometabolismo da barbárie, esta identificada pela generalização da sociedade do desemprego, da precarização do trabalho, da informalização e da degradação do estatuto salarial, consideradas as novas e velhas formas de estranhamento, de fetichismo social e da constituição da subjetividade pelo medo e pela insegurança.

Como sinal deste processo, citam-se a destruição e a reconstrução de coletivos de trabalho que possibilitam a inclusão de novos trabalhadores para compor o perfil do novo homem, aberto aos novos ideais de produtividade e desempenho nas empresas e/ou setor público. Desta forma, o capital consegue sedimentar e operar espaços de captura da subjetividade. Dá-se a constituição de uma nova hegemonia capaz de articular coerção capitalista e consentimento/persuasão do trabalhador. Como esclarece Oliveira (2012, p. 5, grifos nossos), "[...] o consentimento sempre foi o produto de um conflito de classes em que os dominantes, ao elaborarem sua ideologia, que se converte na ideologia dominante, trabalham a construção das classes dominadas à sua imagem e semelhança".

Esta captura tende ao esquecimento das experiências e resistências passadas, possibilitando a construção ideopolítica de um novo mundo de colaboração e de consentimento para os ideais capitalistas (ALVES, 2011). Tais mudanças operadas pelo sistema na busca de se reestruturar acabam generalizando conceitos e ideias mercantis na vida, no trabalho, no lar e no lazer dos sujeitos sociais. Assim, os critérios de produtividade e de desempenho saem do universo da empresa e se disseminam pela sociedade.

Esses elementos ora expostos sinalizam mudanças tanto no âmbito da produção como no da organização e gestão da força de trabalho, além das refuncionalizações do papel do Estado e de suas estratégias de resposta à reprodução da classe trabalhadora.

Além das mudanças acima ressaltadas, a partir do contexto de crise postula-se uma hegemonia ideocultural jamais vista em tempos anteriores, possibilitada pela emergência de novas práticas culturais e maneiras dominantes. Nesta direção, a pósmodernidade chega como a representante da lógica cultural do capitalismo avançado, tornando-se integrada à produção de mercadorias, anunciando, entre vários elementos, a mudança na estrutura dos sentimentos, das práticas, das formas discursivas, da 
sensibilidade, dos hábitos e atitudes de consumo, da aceitação do fragmento, do efêmero, do caótico.

Trata-se de um momento em que a filosofia vive um pragmatismo na nova forma de produção, a partir de acumulação flexível; esta

[...] caracteriza-se pelo surgimento de setores de produção inteiramente novos, novas maneiras de fornecimento de serviços financeiros, novos mercados e, sobretudo, taxas altamente intensificadas de inovação comercial, tecnológica e organizacional (HARVEY, 1997, p. 140).

Neste momento experimenta-se uma das mais bárbaras e extensas crises orgânicas e estruturais do capital e se presencia a conformação de um tipo de consciência que se apresenta de forma fugidia, efêmera e superficial; uma consciência correspondente à crise em meio a tantas inseguranças: medo da perda do emprego, ainda que precarizado, terceirizado, subcontratado, da valorização pelo consumo descartável, seja de objetos de luxo ou de tranquilizantes que ajudem a dominar os sentimentos difusos.

Assim, neste momento histórico em que se advoga a suposta crise das abordagens marxistas para a análise da realidade, a teoria social, ou melhor, as ciências humanas se aterão a construir de forma eclética uma nova resposta para se pensar a realidade, já que sua funcionalidade contribui para a ordem capitalista através da mediação manipuladora da esfera da consciência e da subjetividade. Isso consiste no abandono da razão dialética que se expressa pelo neoliberalismo econômico e pelo positivismo, ou na sua versão atualizada, o neopositivismo, que se transforma em ideologia a serviço da manutenção da ordem burguesa na superação da crise do capitalismo. Cabe fazer uma ressalva sobre este novo conservadorismo, que inclui o positivismo na trama de suas abordagens.

Como observa Santos (2007):

Se, no período anterior a 1848, o conservadorismo possuiu tons reacionários e anticapitalistas, após este momento histórico, marcado pelas ameaças cada vez mais concretas do movimento operário, o conservadorismo vai dar as mãos ao positivismo, fundando as modernas ciências sociais (tornando-se) um importante componente da cultura burguesa do período da decadência ideológica [...]. A atenção dos conservadores se voltará para a construção de um corpo de conhecimentos que, favorecendo a gestão da ordem burguesa [...] permita controlar e regular suas crises e, assim, superar a ameaça revolucionária (SANTOS, 2007, p. 42-43).

O conservadorismo deve ser pensado como expressão de um tempo e espaço historicamente próprios, para que não se percam as particularidades que assume. Com as mudanças no padrão de produção e reprodução do sistema capitalista, várias dimensões da vida sociocultural também são alteradas. Na particularidade da profissão de Serviço Social no contexto da pandemia, há a intensificação da burocratização da vida social em decorrência das novas exigências de proteção com a utilização de tecnologias da informação. 


\section{O SERVIÇO SOCIAL NA PANDEMIA: A BUROCRATIZAÇÃO DA VIDA SOCIAL}

Na área de produção do conhecimento do Serviço Social já foi aventado por vários teóricos que a sua institucionalização como profissão tem sua gênese no capitalismo dos monopólios, permitindo, a partir de então, a fomentação de seu espaço sócioocupacional, dado pela sua funcionalidade no âmbito da divisão sociotécnica do trabalho no capitalismo.

Esta profissão se desenvolve e se legitima por diversas transformações no âmbito do seu exercício e de sua formação profissional, a depender do momento histórico posto pelas necessidades/mudanças do capitalismo, pelas correlações de forças e pelas lutas de classe que conformam as condições materiais e intelectuais possíveis na apreensão do seu movimento, no entorno da profissão e da sociedade.

Por se tratar de uma profissão, há que se considerar que a fonte das demandas profissionais no âmbito da divisão sociotécnica e intelectual do trabalho é fonte que produz e reproduz uma modalidade de intervenção, e exercício sincrético e imediato de manipulação de variáveis empíricas e comportamentais, já que o cotidiano é o local onde se efetiva esta intervenção profissional, permeado pela burocratização administrativa, materializando-se num exercício estritamente manipulador.

A prática profissional do Serviço Social tem como característica sempre presente a existência da manipulação planejada, ou seja, interferência e rearranjo de variáveis empíricas nos espaços profissionais para possibilitar uma intervenção posterior (MARANHÃO, 2016, p. 175).

Uma das tendências sobre a interferência e o rearranjo de variáveis empíricas é a burocratização da vida social, uma práxis típica da burguesia que se torna indispensável ao funcionamento das instituições, mas que empobrece a ação humana. "O caráter repetitivo da ação burocrática bloqueia o contato criador do sujeito [...] com a realidade, substituindo a apropriação do objeto pelo intelecto por uma manipulação vazia de dados, segundo esquemas formais preestabelecidos" (COUTINHO, 1998 apud MARANHÃO, 2016, p. 177).

Desse modo, a práxis burocrática da instituição transforma a realidade social em regras formais de atendimento e intervenção profissional, em que a sistematização da empiria não utiliza as mediações que propiciem ao profissional a aproximação das determinações do fenômeno a partir da totalidade do ser.

Na pandemia, o que já era usual na prática burocratizada torna-se ainda mais uma preocupação, pois para estabelecer um padrão de eficiência em resposta às expressões da questão social, o instrumental operativo enquadrado nas tecnológicas de informação opera numa escala de metas estabelecidas num refinado meio de controle da população usuária dos serviços.

A priorização da técnica pelo saber orientado institucionalmente subordina o profissional ao saber disciplinado e regula a ação profissional. Neste processo, os serviços e programas são instrumentalizados sob o fazer profissional. Segundo lamamoto (2007): 
A institucionalização das ações profissionais e as entidades empregadoras passam a ser vistas invertidamente como 'obstáculos' para o exercício profissional, ao invés de pressupostos e condições de trabalho instigantes da prática criadora (IAMAMOTO, 2007, p. 198).

Os novos tempos exigem cada vez mais uma atuação adequada aos novos ritmos de desenvolvimento social, econômico e político, sem perder de vista os interesses da classe trabalhadora e de sua família. A atuação é fundamental neste processo em que o profissional tem como dever participar de programas de socorro à população no atendimento e defesa de seus interesses e necessidades, como determina o Código de Ética de 1993 dos assistentes sociais. Assim, ocorre a reafirmação da valorização do profissional de Serviço Social no atendimento à população nos diferentes espaços sócioocupacionais, numa realidade desafiadora em que os usuários se tornam partícipes de um mesmo processo.

Com a disseminação do trabalho remoto no atendimento à população, é preciso atender às necessidades da totalidade do ser social no cuidado na intervenção com o aprimoramento das competências que norteiam a profissão. Não há uma regulamentação que permita o atendimento à população de forma online ou por videoconferência, pois esta prática pode prejudicar a qualidade dos serviços, a depender da situação a ser respondida ou investigada pelo profissional. É preciso garantir o sigilo profissional, que pode ser comprometido pela ação profissional de forma remota. Esta é uma realidade que pode fragilizar o andamento da intervenção profissional e exigir outras formas de enfrentamento.

O desmonte e o desfinanciamento do tripé das políticas da seguridade social vêm, a longo prazo, se intensificando. A política de assistência social, que compõe esse tripé, desde 2017 até 2018 teve um corte, em média, de 30\% de seus recursos². Essa política não tem, legalmente, um percentual obrigatório a ser despendido nas suas ações, programas, projetos, serviços e benefícios, o que deixa seus gestores à vontade para efetuar cortes e ajustes. Nos Centros de Referência da Assistência Social (CRAS) e nos Centros de Referência Especializados da Assistência Social (CREAS), foram cortados, em média, 10 milhões de atendimentos na rede básica, o que se soma à redução de 280 mil atendimentos para a população em situação de rua.

Apesar dos cortes nestes serviços, a política de assistência tornou-se indispensável no enfretamento das consequências da pandemia da COVID-19, por ter como público-alvo a população vulnerável. A população é atendida através do agendamento, priorizando-se os casos individualizados graves e mais urgentes; o acompanhamento é feito de forma remota. O trabalho dos profissionais nesta política é respaldado pela Portaria $\mathrm{n}^{\circ} 337$, de 24 de março de 2020, que dispõe medidas para o enfretamento de saúde pública no âmbito do Sistema Único de Assistência Social (SUAS), ao considerar a assistência social como uma política com papel fundamental na proteção da população mais vulnerabilizada. Estabelece como medidas a adoção de regime de jornadas em turnos de revezamentos e a flexibilização das atividades dos usuários no âmbito do Centro de Referência de Assistência Social (CRAS) e do Centro de Referência Especializado de

\footnotetext{
${ }^{2}$ Em 2017, o corte foi de 29,76\%. Em 2018, de 37,52\%. E em 2019, de 29,16\% (CONSELHO NACIONAL DA ASSISTÊNCIA SOCIAL, 2006).
}

Temporalis, Brasília (DF), ano 21, n. 41, p. 53-69, jan./jun. 2021. | ISSN 2238-1856 
Assistência Social (CREAS), com vistas a evitar a aglomeração e a redução da circulação de pessoas.

De acordo com as projeções realizadas pela Comissão Econômica para a América Latina e o Caribe (CEPAL) no Relatório Especial COVID-19, as pessoas com mais de sessenta anos algo em torno de $13 \%$ da população da região ( 85 milhões de pessoas) - enfrentam a maior mortalidade na pandemia; isso significa que sua demanda por cuidados de saúde especializados é maior. Além disso, o isolamento em que muitas delas vivem limita sua capacidade de responder à doença, cria riscos para sua segurança alimentar e pode afetar sua saúde mental.

A política de previdência, desde 2003, passa por processos de contrarreformas 3 com redução de benefícios, aumento do tempo de contribuição e idade para concessão de benefícios previdenciários, e retirada de direitos. Associada à reforma trabalhista que legalizou o trabalho intermitente, o trabalho remoto e o teletrabalho, alinhada à lei das terceirizações, passou a legitimar a flexibilização e a precarização das relações e dos contratos de trabalho, levando para a informalidade muitos trabalhadores, que ficaram sem acesso aos seguros previdenciários.

No campo da saúde, a tragédia anunciada se concretizaria: as superlotações, a insuficiência de equipamentos de segurança e de insumos básicos para o atendimento nas unidades, a precariedade dos equipamentos de assistência, o quantitativo mínimo de profissionais que estão na linha de frente. Em muitas instituições, os equipamentos de proteção têm sido, apenas, máscaras e jalecos, o que não se configura como equipamentos individuais de proteção, já que estes incluem macacões, viseiras, luvas, botas e máscaras, entre outros. Há de se levar em consideração o tempo de uso desses equipamentos pelos profissionais, dado o risco de contaminação.

No que se refere ao trabalho profissional, o Conselho Federal de Serviço Social (CFESS) emitiu uma nota intitulada Orientações sobre o exercício profissional diante da pandemia do coronavírus (COVID-19):

Em relação especificamente ao trabalho do Serviço Social, as/os profissionais devem decidir com autonomia (preferencialmente de forma coletiva) sobre a forma de atendimento mais adequada em cada situação, de modo a atender às orientações [...], assim como proteger a saúde do/a profissional e do/a usuário/a. No entanto, caso decidam por atendimentos por videoconferência, estes devem ter caráter absolutamente excepcional, considerando a particularidade deste momento (CONSELHO FEDERAL DE SERVIÇO SOCIAL, 2020, p. 1).

Independentemente da excepcionalidade do contexto pandêmico, as condições da autonomia profissional devem ser exigidas, conforme preconiza a Resolução CFESS 493/2006 (CONSELHO FEDERAL DE SERVIÇO SOCIAL, 2006), que dispõe sobre as condições éticas e técnicas do exercício profissional da/o assistente social. Apesar das normatizações e da lei que regulamenta a profissão, ainda é comum o envolvimento do instrumental técnico operativo em que as atribuições dos profissionais são redimensionadas no âmbito do controle e monitoramento da população pobre. Com isso,

3 O termo contrarreforma foi utilizado por Behring (2003) para analisar os processos de regressão e desestruturação das conquistas e direitos no bojo da seguridade e da proteção social. 
medidas de seletividades são ainda mais intensificadas no enfrentamento das expressões da questão social. Esta realidade só agrava as contradições da desigualdade social. Um dos problemas dessa prática é a padronização e a tecnificação do trabalho que gerencia sistemas autoexplicativos aparentemente isentos de intencionalidade política (GUERRA, 2016, p. 91).

A pandemia tem desvelado os processos de desigualdades sociais e econômicas, que devem crescer, dadas as projeções da OIT, em todos os países da região, "com aumento no índice de Gini entre 0,5\% e 6\%". Grandes grupos populacionais que vivem em condições crônicas de insegurança econômica são e estarão vulneráveis à perda de renda do trabalho (COMISIÓN ECONÓMICA PARA AMÉRICA LATINA Y EL CARIBE, 2020, p. 1).

Esses novos desafios que correspondem à dinâmica dos serviços prestados precarizam as ações profissionais das mais diversas formas, pois com o trabalho remoto e o revezamento nas escalas de trabalho em alguns campos que são considerados não essenciais, há uma potencialidade do prolongamento da jornada de trabalho. Isso porque o profissional se conecta em tempo integral ao campo de atuação, com respostas ágeis e prontas às demandas que chegam. A efetivação dos preceitos da ética profissional é desafiadora, principalmente no que se refere ao sigilo profissional. Assim,

[...] não se pode reduzir o espaço ocupacional do assistente social a uma prática profissional rotineira, burocratizada, empiricista e tarefeira, tal como se constata com expressividade nas instituições, a qual não expressa mais do que um saber alicerçado no senso comum e uma falta de reconhecimento da identidade profissional do assistente social. (IAMAMOTO, 2007, p. 163).

Sem perder de vista as determinações sanitárias do país no contexto da pandemia, cumpre redefinir nossas ações com base nos parâmetros dos fundamentos da ética profissional, pois é pelos princípios do código profissional que somos direcionados, apesar dos limites postos pela dinâmica desumana do sistema capitalista.

De acordo com lamamoto:

Deve haver um diálogo íntimo com as fontes inspiradoras do conhecimento e busca elucidar seus vínculos sócio-históricos, localizando as perspectivas e os pontos de vista das classes através dos quais são construídos os discursos: suas bases históricas, a maneira de pensar e interpretar a vida social das classes (ou segmentos de classes) que apresentam esse discurso como dotado de universalidade, identificando novas lacunas e omissões (IAMAMOTO, 2007, p. 184).

A pandemia intensificou uma tendência que já vinha sendo desenvolvida em instituições para incorporar na intervenção profissional novas competências que extrapolam as especificidades da profissão, com o manuseio de técnicas e instrumentos cada vez mais conformados às necessidades do controle e administração das manifestações da questão social.

Tornou-se lugar-comum, no que se refere à gênese do Serviço Social, remeter à questão social o lócus desta profissão, requisitando variadas formas de intervenção, já que o seu 
objeto é recortado em múltiplos problemas que necessitam ser respondidos no tocante aos recursos para o público-alvo. Desse modo, “[...] aprisionado na lógica hierárquica e na mecânica estabelecida no jogo institucional, o profissional remete a problemática das refrações da 'questão social' sempre para outras instâncias, ainda que mesmo do próprio Serviço Social” (NETTO, 2006, p. 94, grifos nossos). Desta forma, equaliza modelos abstrato-formais para a sua intervenção. Esta realidade exige dos profissionais uma intervenção essencialmente procedimental.

Identificam-se, pois, alguns traços, como: uma formação aligeirada, flexível e mercantilizada e uma atuação tecnicista no mercado de trabalho, além de uma produção superficial, fragmentada e relativizada. Os prejuízos para a formação incluem a precarização das relações de trabalho e das condições do estágio supervisionado. Dissemina-se, seja no âmbito da academia, seja nos espaços de trabalho, a lógica individualista e concorrencial que não oferece um mínimo de estabilidade no trabalho.

Um dos debates que têm se apresentado no campo da formação e do exercício profissional consiste em apreender a processualidade e os desafios das atuais tendências contemporâneas em relação aos vetores do conservadorismo, que têm se expressado de várias formas - sobretudo pelo pragmatismo e pelo ecletismo teórico - nos discursos e nas modalidades de intervenção profissional. As novas exigências do capitalismo no século XXI afetam o Serviço Social e a dimensão interventiva - as demandas profissionais, o arsenal técnico operativo e as formas de enfrentamento das expressões da questão social - e tornam compatível o trato teórico da questão social a partir de proposições políticas voltadas à erradicação da pobreza e à redução da desigualdade de renda. Muitos conceitos aparecem desvinculados da totalidade histórica, pontuados apenas pela caracterização das suas expressões fenomênicas, já que a intervenção abre espaço para práticas pragmáticas e burocráticas, que visam manipular e ordenar a vida social dos grupos sociais à dinâmica institucional.

Corroborando a afirmação de Guerra (2013, p. 2), “[...] o sincretismo e o pragmatismo caracterizam o modo de ser do Serviço Social, que abre espaço para as tendências (neo)conservadoras, tanto em sua dimensão interventiva como na intelectual". Essa discussão torna-se relevante, pois viabiliza a aproximação com o processo de formação acadêmica, que deve estar concatenado com os desafios contemporâneos, constituindo um processo em permanente construção. Ao se discutir sobre condições/relações de trabalho que se pautam pelo cotidiano, deve- se viabilizar a materialização do projeto ético-político profissional, projeto este que deve ser concebido como uma referência para a formação e o exercício profissional (MEDEIROS, 2020, p. 12).

A fim de contribuir com o fortalecimento do pensamento crítico no âmbito da profissão, faz-se necessário ultrapassar os reducionismos, as influências pragmáticas e o ecletismo que circundam o Serviço Social.

A ascensão do conservadorismo reforça a formação aligeirada em Serviço Social e conduz à precarização do trabalho, tendendo a agravar a dicotomia teoria e prática à medida que são restringidos os instrumentos sociopolíticos de embate no exercício profissional, aumentando o abismo entre as condições materiais de atuação e os desígnios constantes no projeto ético-político profissional (KELLER, 2019, p. 10). 
Como o projeto ético-político está em disputa, há a necessidade de se reafirmar, mais do que nunca, que o projeto de formação e de sociabilidade deve dirigir-se à emancipação humana.

As implicações deste processo, no contexto de crise do capital que se acirra com a pandemia da COVID-19, devem ser apreendidas sob uma perspectiva crítica, aliada ao compromisso teórico-metodológico e ético-político, na direção do desvelamento sóciohistórico da realidade social, tendo em vista que nossa matéria é o tempo presente.

\section{CONCLUSÃO}

Com a crise estrutural do capital no contexto de uma pandemia sem precedentes que assola o mundo, o sistema do capital demonstrou mais uma vez a sua destrutividade, impulsionando uma série de contradições que ameaçam a própria existência da humanidade. Particularmente na realidade brasileira, verifica-se que a função do Estado é demonstrada no investimento, mesmo que precário, dos serviços essenciais.

Para manter sob controle os reflexos acirrados das expressões da questão social, houve a ampliação das redes de serviços, das políticas sociais, dos programas de transferência de renda, do saneamento básico, da previdência e de benefícios eventuais como o auxílio emergencial.

Por outro lado, a pandemia demonstrou a precarização ainda maior dos serviços e do trabalho; em nome da sobrevivência, o trabalho remoto tornou-se central nas discussões. A nova dinâmica da produção e do consumo trouxe benefícios no que se refere à comodidade dos que podem pagar e prejuízos aos que precisam se submeter às diversas modalidades de inserção no trabalho.

O SUS, em tempos da COVID-19, tem se mostrado extremamente necessário, ainda que sem recursos e infraestrutura suficientes para atender a população, que dele tanto necessita. Problemas que se acumularam e se avolumaram, quando se pensa nas enormes filas, na reduzida capacidade de atendimento por falta de insumos básicos e de profissionais para contemplar a demanda crescente, na falta de equipamentos, como respiradores para aqueles que estão nas UTIs, colocam dilemas profissionais enormes.

As superlotações, a insuficiência de equipamentos de segurança e de insumos básicos para o atendimento nas unidades de saúde, a precariedade dos equipamentos de assistência, o quantitativo mínimo de profissionais que estão na linha de frente das instituições de saúde e socioassistenciais têm gerado o abandono de plantões de vários profissionais, principalmente médicos, devido à intensa demanda de usuários e ao risco elevado de contaminação e morte.

Esse contexto traz gigantescos desafios para a profissão, num momento em que a direção socioestratégica posta pelos referenciais sócio-ontológicos do marxismo consegue adentrar com força hegemônica no corpo profissional, o que não significa que outras perspectivas não estejam na disputa pela direção ideológica e teórica. Esta direção é contraditada pelos entendimentos mediados por uma produção teórica e ações práticas instrumentalizadas, através do trabalho remoto padronizado, com atividades 
direcionadas ao ajustamento da população. Coloca-se para o exercício profissional um novo direcionamento de intervenção, que deve estar atento à liberdade e à autonomia como valores éticos centrais.

Nessa direção, lança-se a ideia do suposto fim da história, da necessidade de outras abordagens que consigam "deitar o olhar nas especificidades" do micro, do local, do cotidiano e do efêmero. Apesar da produção da vacina, este novo contexto demonstra um descontrole da pandemia que requer um movimento estratégico a fim de amenizar os efeitos do conservadorismo na atuação profissional, explicitado pela negação dos avanços da ciência, num verdadeiro negacionismo e obscurantismo quanto às saídas éticas e sociais para a população.

Tais questões não podem ser pensadas dissociadas da totalidade social. Esta processualidade requer um movimento de categorias que permita a busca dos determinantes que conformam a profissão no âmbito da sociedade burguesa, a saber: o movimento da singularidade, da particularidade (o campo das mediações e das tendências dos processos sócio-históricos) e da universalidade.

Muitas das produções do conhecimento na área de Serviço Social, e especialmente no campo da produção crítica, trazem o rótulo do imediatismo e do pragmatismo, numa reatualização do viés neopositivista que tem conduzido o debate para outras fronteiras da descrição, das modulações, das avaliações esquemáticas e confucionistas que se acirram no contexto pandêmico.

O debate atual não pode focar apenas as diversas e cansativas discussões que são travadas na produção acadêmica do Serviço Social pela relação estabelecida entre neoliberalismo e democracia, ou questões do gênero. Cumpre construir referenciais teóricos e metodológicos que possam abordar a complexa relação entre a emancipação política e o horizonte da emancipação humana, pois só assim se torna possível uma reflexão que não caia nas armadilhas de uma análise tecnicista, instrumental e imediatista.

Faz-se necessário mergulhar na ontologia e alcançar seus fundamentos, gênese, dinâmica, desenvolvimento, consolidação, tendências e a função social que cada objeto ocupa em vários contextos sócio-históricos, a fim de que sejam superados os procedimentos formalistas, que tendem a intensificar o processo de alienação ideológica, tornando inviável o desvendamento da realidade.

Com a pandemia, a necessidade de ampliação do orçamento público mostra-se imprescindível. Ainda que as políticas adotadas sejam direcionadas por um modelo focalista e seletivo, não ultrapassando sua forma pontual e imediatista, este momento histórico impõe avançar na garantia universal da proteção social, a fortalecer o elenco das políticas de seguridade social, num contexto de ampliação das desigualdades sociais e do retorno do país ao mapa da fome.

Vê-se que o sistema sociometabólico do capital, com a pandemia da COVID-19, acirra suas contradições e expressões, seja do ponto de vista sanitário, seja do ponto de vista econômico, ou ainda do ponto de vista social e humanitário, ocasionando condições deletérias para os/as trabalhadores/as e para as políticas sociais. 
Nesta trilha argumentativa, ressalta-se mais uma vez a urgência da análise critica da realidade, apontando o compromisso com a qualidade da produção teórica, pois o conteúdo produzido neste contexto de crise/restauração do capital tem levado à formação de práticas e conteúdos cada vez mais fragmentados, alienados e submissos ao processo mercantil.

A análise comprometida e crítica deve ser o fundamento das nossas produções e dos nossos debates.

\section{REFERÊNCIAS}

ALVES, G. Trabalho e subjetividade: o "espírito do toyotismo" na era do capitalismo manipulatório. São Paulo: Boitempo, 2011.

ARCARY, Valério. Os abismos regressivos da história: anotações sobre a crise econômica internacional (2008-2011). Crítica e Sociedade: revista de cultura política, São Paulo, v. 1, n. 3, dez. 2011.

BEHRING, Elaine Rossetti. Brasil em contra-reforma: desestruturação do Estado e perda de direitos. São Paulo: Cortez, 2003.

BRAZ, Marcelo. Capitalismo, crise e lutas de classes contemporâneas: questões e polêmicas. Revista Serviço Social e Sociedade, São Paulo, n. 111, set. 2012.

COMISIÓN ECONÓMICA PARA AMÉRICA LATINA Y EL CARIBE. El desafío social en tiempos del COVID-19. [S. I.]: ONU, 2020.

CONSELHO FEDERAL DE SERVIÇO SOCIAL (CFESS). Resolução $\mathbf{n}^{\circ}$ 493/2006: dispõe sobre as condições éticas e técnicas do exercício profissional do assistente social. Brasília (DF): CFESS, 2006. Disponível em: http://www.cfess.org.br/arquivos/Resolucao_493-06.pdf. Acesso em: 25 abr. 2020.

CONSELHO FEDERAL DE SERVIÇO SOCIAL(CFESS). Nota do CFESS: orientações sobre o exercício profissional diante da pandemia do Coronavírus (COVID-19). Disponível em: http://www.cfess.org.br/arquivos/2020CfessManifestaEdEspecialCoronavirus.pdf. Acesso em: 25 abr. Acesso em: 25 abr. 2020.

DEPARTAMENTO INTERSINDICAL DE ESTATISTICA E ESTUDOS SOCIOECONOMICOS (DIEESE). Boletim de Conjuntura, São Paulo, n. 22, maio 2020. Disponível em: https://www.dieese.org.br/boletimdeconjuntura/2020/boletimConjuntura022.html. Acesso em: 20 jul. 2020.

GUERRA, Y. Expressões do pragmatismo no Serviço Social: reflexões preliminares. Revista Katálysis, Florianópolis, v. 16, n. esp., 2013.

GUERRA, Y. Transformações societárias, Serviço Social e cultura profissional: mediações sócio-históricas e ético-políticas. In: MOTA, Ana Elizabete; AMARAL, Ângela (orgs.). 
Cenários, contradições e pelejas do Serviço Social brasileiro. São Paulo: Cortez, 2016. p. 83-110.

HARVEY, D. Condição pós-moderna. 6. ed. São Paulo. São Paulo: Loyola, 1997.

IAMAMOTO, M. V. Renovação e conservadorismo no Serviço Social: ensaios críticos. 8. ed. São Paulo: Cortez, 2007.

INSTITUTO BRASILEIRO DE GEOGRAFIA E ESTATISTICA. Desemprego. Disponível em: https://www.ibge.gov.br/explica/desemprego.php. Acesso em: 11 jun. 2021.

KELLER, Suéllen Bezerra Alves. A ascensão do conservadorismo e o esgotamento do projeto neodesenvolvimentista: implicações profissionais ao Serviço Social. 2019. Tese (Doutorado em Serviço Social) - Programa de Pós-Graduação em Serviço Social, Escola de Humanidades, Pontifícia Universidade Católica do Rio Grande do Sul, Porto Alegre, 2019.

LUKÁCS, G. Ontologia do ser social: os princípios ontológicos fundamentais de Marx. São Paulo: Ciências Humanas, 1979.

MARANHÃO, C. Uma peleja teórica e histórica: Serviço Social, sincretismo e conservadorismo. In: MOTA, Ana Elizabete; AMARAL, Angela (orgs.). Cenários, contradições e pelejas do Serviço Social brasileiro. São Paulo: Cortez, 2016. p. 165-205.

MARX, K. O Capital. São Paulo: Abril Cultural, 1983. (t. 1).

MÉSZÁROS, István. Para Além do Capital: Rumo a uma teoria da transição. São Paulo: Boitempo, 2002.

MEDEIROS, Milena Gomes. Conservadorismo e serviço social: algumas notas. Revista Humanidades em Perspectivas, v. 2, n. 5, jul./dez. 2020.

MÉSZÁROS, István. O século XXI: socialismo ou barbárie?. São Paulo: Boitempo, 2012.

MOTA, Ana Elizabete. Cultura da crise e seguridade social: um estudo sobre as tendências da previdência e da assistência social brasileira dos anos 80 e 90. São Paulo: Cortez, 2008.

NETTO, J. P. Capitalismo monopolista e serviço social. São Paulo: Cortez, 2006.

OLIVEIRA; Francisco. Hegemonia às avessas. Revista Piauí, São Paulo, ed. 4, jan. 2012. Tribuna livre da uta de classes.

SANTOS, Josiane Soares. Neoconservadorismo Pós-Moderno e Serviço Social Brasileiro. São Paulo: Cortez, 2007.

SUDRÉ, Lu. Ricardo Antunes: "Pandemia desnuda perversidades do capital contra trabalhadores”. Brasil de Fato, São Paulo, 27 jun. 2020. Disponível em:

https://www.brasildefato.com.br/2020/06/27/ricardo-antunes-pandemia-desnuda-perversidadesdo-capital-contra-trabalhadores. Acesso em: 10 dez. 2020 
Angélica Luiza Silva Bezerra Trabalhou na concepção, delineamento, análise e interpretação dos dados e na redação do artigo.

Professora do Curso de Serviço Social da Unidade Educacional - Palmeira dos Índios pela Universidade Federal de Alagoas (UFAL). Atualmente é Coordenadora de Estágio do Curso de Serviço Social da mesma instituição. Mestre em Serviço Social pela (UFAL) e Doutora em Serviço Social pela (UFPE). Membro do Grupo de Pesquisa Sobre Reprodução Social.

Milena Gomes de Medeiros Trabalhou na concepção, delineamento, análise e interpretação dos dados e na redação do artigo.

Professora do Curso de Serviço Social pela Universidade Federal de Alagoas (FSSO/UFAL). Mestre em Serviço Social pela (UFRN) e Doutora em Serviço Social pela (UFPE). Atualmente é Vice Tutora na área de Serviço Social na Residência Multiprofissional em Saúde do Adulto e do Idoso/Hospital Universitário Prof. Alberto Antunes (UFAL). Membro de Comissões na Faculdade de Serviço Social (FSSO/UFAL). Membro de conselhos editoriais Membro do Grupo de Pesquisa Sobre Política Pública e Processos organizativos da sociedade. 